\title{
Research on Scientific Research Performance of Humanities and Social Sciences in China's First-class Universities Based on SE- DEA
}

\author{
Xueqian Zhang* \\ School of Public Affairs, University of Science and Technology of China, 96 Jin Zhai Road, Hefei \\ 230000, Anhui Province, China
}

\begin{abstract}
The research efficiency of humanities and social sciences in 41 first-class universities in China was measured based on Super Efficiency DEA method. It is found that most universities have higher research efficiency, but the scale efficiency is lower, and the universities with ineffective scale are mostly large-scale universities. Through analysis, the efficiency of universities is driven by insufficient input of resources, inefficiency is caused by insufficient output of results and redundancy of input of resources. There are the following suggestions: one recommends that large-scale universities should appropriately reduce the scale of scientific research; secondly, "pseudo-effective universities" should strengthen output-oriented to achieve real efficiency; at the same time, inefficient universities can improve from the aspects of technology and management capabilities.
\end{abstract}

Keywords: first-class universities, research performance, super efficiency DEA

DOI: $10.7176 / \mathrm{JESD} / 10-10-17$

Publication date:May $31^{\text {st }} 2019$

"The Overall Plan for Coordinately Advancing the Construction of World First-class Universities and First-class Disciplines" pointed out that Chinese universities have problems of identity solidification and lack of competition, and proposed reform measures of "performance-oriented". Performance is a relative concept, one kind of performance measurement, refers to the input-output ratio, that is, efficiency. In this context, this paper conducts an empirical analysis of the research efficiency of humanities and social sciences in China's first-class universities, hoping to find out the characteristics and shortcomings of the construction of Chinese universities, and make suggestions for promoting the construction of world-class universities and the development of higher education.

\section{Literature review}

The evaluation methods of university research efficiency are diverse and mainly quantitative methods, such as data envelopment analysis and stochastic frontier analysis. Wang Ning (2019) used the DEA to analyze the efficiency of 40 universities in China, and found that the excessive investment in research funding is the main factor affecting the efficiency of scientific research in universities. Chen Lin and Yue Zhenxing (2018) used stochastic frontier analysis to measure the efficiency of scientific research in 18 universities with industry characteristics in China, pointing out that the efficiency of scientific research was mainly driven by funds, and universities with fewer researchers were more efficient. The application of DEA and SFA by Horne Jocelyn and Hu Baiding (2008) analyzes the cost efficiency and technical efficiency of universities in different regions.

The construction of university efficiency evaluation index system is relatively scientific. Academic resources, tutors and education funds are generally used as input indicators, scientific research achievements and personnel training are the output indicators. For example, Garcia-Aracil and Adela (2013) use the number of tutors and research funds as input indicators, the number of graduate students and scientific research results as output indicators. Ou Jinshi and Hong Jiasheng (2010) used the total expenditure and equipment assets as inputs, and the number of graduates and the number of research winners as outputs. Johnes (2014) added other material resources indicators such as teaching and research equipment, and books in inputs or outputs.

It can be seen that the research on the evaluation of scientific research efficiency in universities at home and abroad has been relatively mature, but in general there are still two shortcomings. (1) The input or output evaluation indicators are comprehensive, but still lack representativeness, such as the selection of human capital, monetary capital and material capital. (2) Output indicators are rich, but not hierarchical, and are not divided into general output and excellent output. In view of these two shortcomings, this paper makes the following research. 


\section{Theory and method}

\subsection{Super Efficiency Data Envelopment Analysis (SE-DEA)}

Data Envelopment Analysis (DEA) is a relative efficiency analysis method, proposed by American scholars Charnes, Cooper and Rhodes (1978). It is to evaluate the relative effectiveness of similar decision making units (DMUs) with multiple inputs and outputs. The first model they proposed was called the CCR model. Since then, Fare, Gross-kopf and Logan, and Banker, Charnes, and Cooper proposed the VRS model in 1983 and 1984 , respectively. Tone Kaoru proposed SBM model in 2001, and so on (Cheng Gang, 2014). These models can only classify DMU as "effective" and "ineffective", and can't further compare the efficiency of "effective" DMU. So, Andersen and Petersen proposed a method to analyze the effectiveness of effective DMU, this method is called Super-Efficiency Model, the core of which is to remove the evaluated DMU from the reference set, the efficiency of the evaluated DMU is calculated based on the frontiers of other DMUs, the effective value of the effective DMU is generally greater than 1, further distinguishing them, the output-oriented CRS super-efficiency model can be expressed as follows (Andersen P, 1993):

$$
\begin{array}{ll}
\max \varphi & \text { s.t. } \sum_{\substack{j=1 \\
j \neq k}}^{n} \lambda_{j} x_{i j} \leq x_{i k} \\
& \sum_{\substack{j=1 \\
j \neq k}}^{n} \lambda_{j} x_{r j} \geq \varphi y_{r k} \\
& \sum_{\substack{j=1 \\
j \neq k}}^{n} \lambda_{j}=1 \\
\lambda \geq 0
\end{array}
$$

$\mathrm{i}=1,2, \ldots, \mathrm{m} ; \mathrm{r}=1,2, \ldots, \mathrm{q} ; \mathrm{j}=1,2, \ldots, \mathrm{n}(\mathrm{j} \neq \mathrm{k})$, where Xik and Yrk represent the $\mathrm{i}$-th input and $\mathrm{r}$-th output of the $\mathrm{k}$-th DMU respectively, $\lambda$ represents the linear combination coefficient of the DMU, and $\phi$ is the model optimal solution. In addition, the technical efficiency value (integrated technical efficiency TECRS) obtained in CRS DEA can be decomposed into scale efficiency (SE) and pure technology efficiency (TEVRS). The relationship between them is TECRS $=\mathrm{TEVRS} \times \mathrm{SE}$. The nature of scale efficiency can be determined by comparing whether NIRS technical efficiency and VRS technical efficiency are equal, if the two are equal, DMU has incremental scale returns, and if they are unequal, diminishing scale returns.

\subsection{Indicators and framework}

For the input and output of the evaluated unit, the smaller the input, the better, and the larger the output, the better. According to the quantitative relationship between the decision-making unit and the evaluation indicators (Cheng Gang, 2014; Golany B, 1989), and the specific setting of the input and output indicators by the above scholars. This paper proposes an indicator system for analyzing the research efficiency in China's first-class universities (Table 1). The data comes from the Social Science Statistics Summary and official websites of universities.

Table 1. Research efficiency index system of humanities and social sciences in China's first-class universities

\begin{tabular}{lll}
\hline \hline \multirow{2}{*}{ input indicators } & general indicators & output indicators \\
\cline { 2 - 3 } $\begin{array}{l}\text { social science activity } \\
\text { personnel }\end{array}$ & $\begin{array}{l}\text { national social science fund } \\
\text { winner }\end{array}$ & Cheung Kong Scholars \\
\hline internal expenditures & academic paper & works \\
\hline $\begin{array}{l}\text { scientific research } \\
\text { platform }\end{array}$ & research advisory report & $\begin{array}{l}\text { national and ministerial } \\
\text { awards }\end{array}$ \\
\hline \hline
\end{tabular}




\section{Empirical results}

3.1 Overall performance: China's first-class universities have higher comprehensive efficiency, but scale efficiency is lower and returns are diminishing

In the field of humanities and social sciences, it has been found through statistics that the research resources input and results of the 41 universities in China (the lack of data of the National University of Defense Technology) from 2008 to 2017 are as follows. (1) Resource input: people in social science activities are 403,515, the internal expenditure for research and development funds was 27.489 billion yuan, and the national-level scientific research platform accumulated 1,085. (2) Outcome output, there are 6,836 national social science fund recipients (general projects and youth projects) as general indicators for talent training, 285 professors of Cheung Kong Scholars representing outstanding talents; 508,865 academic papers and 55,069 works; 18,133 research and consulting reports were adopted, and 1931 national and ministerial awards.

The research efficiency of the first-class universities in humanities and social sciences in the past ten years. Based on the non-oriented SE-DEA analysis (measuring tool is my dea 1.0), the research efficiency of the humanities and social sciences of the universities is 1.282 , the pure technical efficiency is 1.370 , and the scale efficiency is 0.935 . It can be seen that the humanities and social sciences of 41 first-class universities are efficient in ten years as a whole. That is to say, under the current situation of resource input, there are more output results, but the scale efficiency shows that they are not in the optimal scale and does not play the theoretical maximum production capacity. Moreover, the nature of scale efficiency shows a diminishing return on scale. In other words, we can further improve the efficiency of research and increase production capacity by reducing the scale.

3.2 University performance: most universities shows that the overall efficiency is effective, but the scale efficiency is ineffective

The research efficiency of humanities and social sciences in 41 first-class universities is as follows. (1) There are 24 universities with a comprehensive efficiency in humanities and social sciences (accounting for $58.5 \%$ of 41 universities), among them, the super efficiency values are ranked from large to small, the top three are South China University of Technology, Shanghai Jiaotong University, and University of Science and Technology of China, the super efficiency values are 5.761, 2.984 and 2.095, respectively. (2) There are 29 universities with pure technical efficiency $(70.7 \%)$, the highest efficiency value is still the above three universities. (3) There are 15 universities (36.6\%) with effective scale, respectively, South China University of Technology, Shanghai Jiaotong University, Minzu University of China, Zhengzhou University, Lanzhou University, Beijing Normal University, Nanjing University, Beihang University, Central South University, Chongqing University, Hunan University, Fudan University, Xi' an Jiaotong University, Tongji University and Northeastern University; there are 12 universities (29.3\%) with increasing returns to scale, specifically University of Science and Technology of China, China Agricultural University, Ocean University of China, Southeast University, Dalian University of Technology, University of Electronic Science and Technology of China, Xinjiang University, Beijing Institute of Technology, Tianjin University, Northwest A\&F University, Northwestern Polytechnical University and Harbin Institute of Technology, the remaining 14 are universities with decreasing returns on scale. It can be seen that most of the firstclass universities are efficient in humanities and social sciences research. They have a high utilization rate of the given resources and a large output of achievements, but very few of them are effective in scale. That is to say, for the vast majority of universities, they can improve their scientific research ability by reducing their scale.

\section{Conclusion analysis}

4.1 Overall analysis: the efficiency of scientific research in first-class universities is pseudo-effective and driven by insufficient input

For the 41 universities, the slack of input and output is as follows. (1) Resource input, input slack includes input redundancy (positive value representation) and insufficient input (represented by negative value), the number of social science activity personnel was originally 403,515 , the improvement ratio was $-15.67 \%$, and the insufficient input was -63217 , the target value was 466,732; the internal expenditure was originally 27.489 billion yuan, the improvement ratio was $-5.39 \%$, the insufficient input was -1.480 billion yuan, the target value is 28.970 billion yuan; the national-level scientific research platform has a total of 1100 , the improvement ratio is $11.47 \%$, and the input redundancy is 126 , the target value is 974 . (2)Outcome output, output slack includes insufficient output (positive value representation) and output redundancy (represented by negative value), the number of winners of the national social science fund was originally 6,836 , the improvement rate was $33.72 \%$, the insufficient output was 2,305, and the target value was 9141; the Cheung Kong Scholars were 285, the improvement rate was 23.79\%, 
the insufficient output was 68 , and the target value was 353 ; the academic paper was 508,865 , the improvement ratio was $22.11 \%$, the insufficient output was 112,532 , the target value was 621,397 ; the works was 55,069 , the improvement ratio was $23.25 \%$, the insufficient output was 12,803 , and the target output was 67872 ; the research and consultation report adopted by the relevant departments was originally 18,133, the improvement ratio was $36.39 \%$, the insufficient output was 6,599 , the target output was 24,732 ; the national and ministerial award was 1931 , the improvement ratio was $30.25 \%$, and the insufficient output was 584., the target value is 2515 items.

These results indicate, the output of humanities and social sciences in universities is seriously insufficient, not only because of the insufficient output of "general results" such as the recipients of national social science funds, academic papers, research and consulting reports adopted by relevant departments, but also the "outstanding achievements" are insufficiently produced, such as Cheung Kong Scholars, works, national and ministerial awards, which have a high proportion of improvement. In addition, there are also shortcomings in resource input, including insufficient investment in social science activities personnel and internal expenditures, especially the insufficient input of social science activities personnel. Generally speaking, the research efficiency of humanities and social sciences in first-class universities is not due to the output of more results, but is fundamentally driven by insufficient input, which is a kind of "lack of investment in the pseudo-effective".

4.2 Analysis of universities: universities with efficient research are "pseudo-effective driven by insufficient human capital and monetary capital", and universities with inefficient research are "pure inefficiency constrained by insufficient output and redundant input"

The slack of input and output in efficient universities is as follows. (1) Resource input, the number of social science activity personnel was originally 226,455 , the improvement ratio was $-30.59 \%$, insufficient input of $-69,280$, the target value was 295,735; the internal expenditure was originally 15.380 billion yuan, the improvement ratio was $-21.95 \%$, insufficient input of -3.376 billion yuan, the target value is 18.757 billion yuan; the national-level scientific research platform has a total of 629 , the improvement ratio is $7.26 \%$, the input redundancy is 46 , and the target value is 583. (2)Outcome output, the number of winners of the national social science fund was 4013, the improvement ratio was $39.74 \%$, the insufficient output was 1,595 , and the target value was 5,608; the Cheung Kong Scholars have 198, the improvement ratio is $10.74 \%$, the insufficient output was 21, the target value is 219 ; the academic paper is 319,157 , the improvement ratio is $19.93 \%$, the insufficient output was 63,608 , and the target value is 382,765 ; the works were 35,343 , the improvement ratio was $17.00 \%$, the insufficient output was 6007 , and the target output was 41350; the research and consulting report adopted by the relevant departments was originally 10,121 , the improvement ratio was $47.48 \%$, and the insufficient output was 4,805 ; the target output was 14,926; the national and ministerial awards were 1,260, the improvement ratio was $15.76 \%$, the insufficient output was 199, and the target value was 1459 .

It can be seen that the output of scientific research achievements in first-class universities is insufficient, and the output of "general results" and "excellent achievements" are insufficient, but the input of resources in social science activity personnel and internal expenditure funds is even more insufficient. Therefore, the high efficiency of humanities and social science research in universities is driven by insufficient input, which is "pseudo-effective driven by insufficient human capital and capital capital".

The slack of input and output in inefficient universities is as follows. (1) Resource input, the number of social science activity personnel was 177,060 , the improvement ratio was $3.42 \%$, the input redundancy was 6063 , and the target value was 170,997 ; the internal expenditure was originally 12.109 billion yuan, the improvement ratio was $15.66 \%$, the input redundancy was 1.896 billion yuan, the target value was 10.213 billion yuan; the nationallevel scientific research platform had a total of 471 , the improvement ratio was $17.08 \%$, and the input redundancy was 80 , the target value is 391. (2)Outcome output, the number of recipients of the national social science fund was 2,823 , with an improvement ratio of $25.16 \%$, the insufficient output was 710 , and a target value of 3,533 ; the Cheung Kong Scholars have 87, the improvement rate is $53.50 \%$, the insufficient output was 47, the target value is 134 ; the academic paper is 189,708 , the improvement ratio is $25.79 \%$, the insufficient output was 48,924 , and the target value is 238,632 ; the works are 19,726 , the improvement ratio was $34.45 \%$, the insufficient output was 6,797 , and the target output was 26,523; the research and consultation report adopted by the relevant departments was originally 8012 , the improvement ratio was $22.39 \%$, the insufficient output was 1794 , the target output was 9806; the national and ministerial award was 671 , the improvement ratio was $57.45 \%$, and the insufficient output was 385 , the target value is 1056 items.

The inefficiency of scientific research in universities is not only due to the lack of output such as "general results" and "excellent achievements", but also the social science activities personnel, internal expenditure funds and national-level scientific research platforms are more redundant. The proportion of improvement in output shortage 
and input redundancy is relatively high. Generally speaking, the inefficiency or low efficiency of humanities and social science research in such universities is caused by insufficient output and redundant resources. It is a real and completely "purely ineffective", that is "pure inefficiency constrained by insufficient output and redundant input".

\section{Suggestions}

Through the above analysis, the suggestions are as follows: (1) On the whole, the research of humanities and social sciences in 41 universities in China is efficient, but the scale efficiency is lower, many universities are in a state of diminishing returns. It is recommended that universities with larger scales appropriately reduce the scale of scientific research, such as reducing the number of graduate enrollment. (2) The research efficiency of the humanities and social sciences of universities is pseudo-effective driven by insufficient input. It is recommended that these universities strengthen the output-oriented, achieve true scientific research efficiency. (3) For universities with inefficient research, they are encouraged to improve their research efficiency in terms of technological improvement and management capabilities, such as strengthening the construction of scientific research platforms, as well as establishing modern university management systems.

\section{Acknowledgments}

The research is financed by Chinese Society of Academic Degrees and Graduate Education (CSADGE). No. A12017Y0704-004 (Research on the equity of postgraduate education in China)

\section{References}

Andersen P, Petersen N C. A Procedure for Ranking Efficient Units in Data Envelopment Analysis [J]. Management Science, 1993, 39(10): 1261-1264.

Charnes A, Cooper W W, Rhodes E. Measuring the Efficiency of Decision Making Units [J]. European Journal of Operational Research, 1978, 2(6): 429-444.

Cheng Gang. Data Envelopment Analysis Method and MaxDEA Software [M]. Beijing: Intellectual Property Publishing House, 2014: 151, 27.

Chen Lin, Yue Zhenxing. Research on Evaluation of Scientific Research Efficiency of Universities with Industry Characteristics Based on Stochastic Frontier Analysis Theory [J]. Journal of Higher Education Management, 2018, 12(04):73-80.

Garcia-Aracil, Adela. Understanding Productivity Changes in Public Universities: Evidence from Spain [J]. Research Evaluation, 2013, 22(5): 351-368.

Golany B, Roll Y. An Application Procedure for DEA [J]. Omega, 1989, 17(3): 237-250.

Horne Jocelyn, Hu Baiding. Estimation of Cost Efficiency of Australian Universities [J]. Mathematics and Computers in Simulation, 2008, 78(2-3): 266-275.

Johnes Jill. Efficiency and Mergers in English Higher Education 1996/97 to 2008/9: Parametric and NonParametric Estimation of the Multi-Input Multi-Output Distance Function [J]. Manchester School, 2014, 82(4): 465-487.

Ou Jinshi, Hong Jiasheng, Zhang Liyun. A Comparative Study of Output Efficiency between Public and Private Universities in Taiwan [J]. Research on Economics and Management, 2010, (05): 84-92.

Wang Ning, Wang Luyu. Evaluation of Scientific Research Efficiency in "First-class Universities" Based on Improved DEA Cross Model [J]. Modern Education Management, 2019, (02): 75-80. 